\title{
Colo-Colic Invagination on Lipoma
}

\section{Eddy Oleko Ekuke ${ }^{1 *}$, Pierlesky Elion Ossibi ${ }^{1}$, Ouadii Mouaqit ${ }^{1}$, El Bachir Benjelloun1, Hicham El Bouhaddouti' ${ }^{1}$ Boubacar Efared ${ }^{2}$, Laila Chbani' ${ }^{2}$, Abdelmalek Ousadden', Khalid Mazaz ${ }^{1}$, Khalid Ait Taleb ${ }^{1}$}

\author{
${ }^{1}$ Visceral Surgery Department, Hassan II University Hospital, Fez, Morocco \\ ${ }^{2}$ Anatomy and Pathological Cytology Department, Hassan II University Hospital, Fez, Morocco \\ Email: *Olekoekuke20121982@gmail.com
}

How to cite this paper: Ekuke, E.O., Ossibi, P.E., Mouaqit, O., Benjelloun, E.B., Bouhaddouti, H.E., Efared, B., Chbani, L., Ousadden, A., Mazaz, K. and Taleb, K.A. (2017) Colo-Colic Invagination on Lipoma. Surgical Science, 8, 191-195.

https://doi.org/10.4236/ss.2017.84022

Received: March 15, 2017

Accepted: April 24, 2017

Published: April 27, 2017

Copyright $\odot 2017$ by authors and Scientific Research Publishing Inc. This work is licensed under the Creative Commons Attribution International License (CC BY 4.0).

http://creativecommons.org/licenses/by/4.0/

\begin{abstract}
Intussusception in adults is rare and accounts for $1 \%$ to $5 \%$ of cases of acute bowel obstruction. Moreso, colic intussusception remains exceptional in adults and is usually secondary to an endoluminal lesion. Abdominal intestinal lipomas are rarely responsible for colonic invagination. They are often located on the caecum or the ascending colon and rarely on the left colon. We report the case of colo-colic invagination on a descending colon lipoma in a 50-year-old woman.
\end{abstract}

\section{Keywords}

Bowel Obstruction, Colic Lipoma, Intussusception, Surgery

\section{Introduction}

Intussusception is rare in adults, representing $1 \%$ to $5 \%$ of the causes of acute bowel obstruction in adults and its preoperative diagnosis is difficult and usually delayed [1]. In adults, organic causes are often responsible for the very few cases of intussusception and management is always surgical [1]. We hereby report a rare case of colo-colic invagination on a descending colon lipoma in a 50-yearold woman, whose preoperative diagnosis was suspected on emergency abdominopelvic CT scan.

\section{Case Report}

A 50-year-old female being monitored for hypertension, presented with a 5-day history of a gradually worsening flatus cessation without stool cessation and accompanying periodic vomiting complicated 2 days prior to her admission with complete bowel obstruction and generalized abdominal pain without other associated signs. 
Physical examination found a conscious, hemodynamically stable and afebrile patient. Abdominal exam noted a slightly distended belly with left flank tenderness. Common hernia orifices were free and rectal exam was unremarkable.

Lab tests notably natremia and kaliemia came back unremarkable.

Plain abdominal X-ray came back for large bowel obstruction with colic distension without fluid-air levels

Abdominal CT showed distension of a few small bowel loops, the right and the transverse colon upstream of a colo-colic invagination on a lipoma of the descending colon (Figure 1).

After adequate preparation, patient was admitted to the operating theater for emergent surgery.

Surgical exploration revealed a colo-colic invagination at the level of the left (descending) colon on a lipoma.

Surgical management consisted of segmental resection of the left colon taking up the intussusception with subsequent end-to-end colonic anastomosis.

Histological examination of the surgical specimen came back for lipoma (Figure 2).

Postoperative recovery was uneventful with favorable outcome till date.

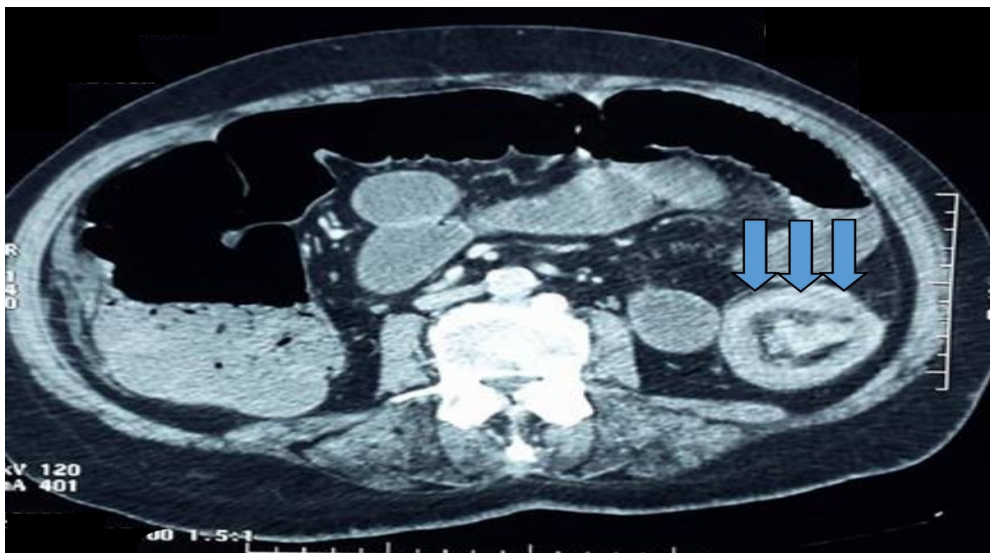

Figure 1. Abdominal CT axial section showing colo-colic invagination on a lipoma of the descending colon.

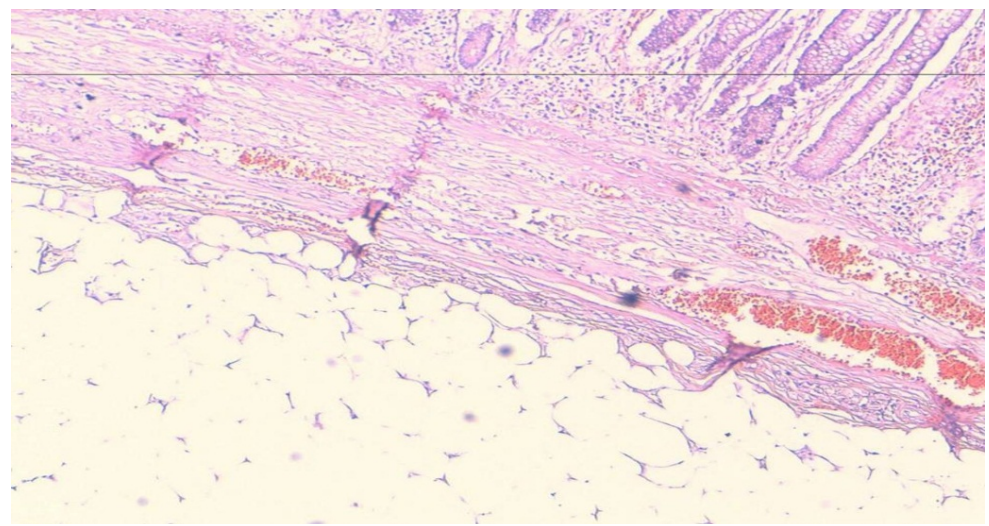

Figure 2. The histological image showing a benign submucosal adipocytic tumor in the colon $(\mathrm{HES} \times 10)$. 


\section{Discussion}

Intestinal intussusception is defined asa telescoping of a segment of the intestine in anotherdistant segment. It is a common occurrence in children yet rare in adults, as only $5 \%$ of cases of intussusceptions involve adult patients [1]. It involves mostly segments of the small intestine $(48 \%-70 \%)$, or could be ileo-colic (25\% - 40\%) and rarely colo-colic (5\% - 18\%) [2] [3]. Distal sigmoid colon forms only account for $2.1 \%$ to $9.4 \%$ of invagination [1].

Colic intussusception is a common condition in children [4]. It is rare in adults and is often secondary to a malignant endo luminal lesion, usually carcinoma. Invagination is rarely the mode of discovery of intestinal lipoma. The latter is often found on the caecum or ascending colon [5] [6] and more rarely on the left colon. Theoretically speaking, lipomas can affect any segment of the digestive tract from the hypopharynx to the rectum. They mostly affect women [7] aged between 50 and 70 years and are usually solitary and submucosal [8]. In about $20 \%$ of cases, lipomas may be multiple and associated with carcinoma [7]. They represent the most frequent benign tumor of the colon, next to adenoma. In most cases, its discovery is fortuitous during an enema or abdominal CT scan as lesions could remain asymptomatic for a long period (with incidence on autopsy estimated at $0.2 \%$ ) [4].

Clinical presentation may be variable. It manifests in a setting of acute bowel obstruction syndrome (abdominal pain, bloating and stool cessation) and even one of a chronic gradually worsening occlusion (incomplete invagination responsible for intermittent spontaneously regressing episodes of bowel obstruction) [1] [2] [3].

Ultrasound is an effective diagnostic tool for both intussusception (classic target sign with a double digestive wall) and lipoma (well-defined hyperechoic lesion surrounded by a normal digestive wall [9] [10] [11]. However, distension and digestive gases limit its performance. CT scan is a sensitive and specific tool for the diagnosis of lipoma [9]. In adults, before peritoneal syndrome or occlusion, CT is considered first-choice imaging tool and could replace ultrasound. In the case of our patient, CT confirmed bowel obstruction, its location and the nature of the obstacle. CT best characterizes the lesion by showing its fatty contingent [12]

Hence, the only pitfall is that of its differential diagnosis with liposarcoma. Conventionally, the latter has a heterogeneous density and a slight enhancement after contrast medium injection. However, even typical lipomas may appear as heterogeneous due to the presence of an underlying fibrovascular tissue. A recent study has sought to evaluate the performance of MRI in the diagnosis of colorectal masses [13]. The appearance of lipoma is characteristic: high signal intensity on FLASH sequences and a complete disappearance of the signal becoming hypo intense on fat-suppression protocol. Endoscopy may reveal a sessile or pediculate soft tissue tumor covered by a normal mucosa and allows biopsies to be performed, or even the tumor resection if symptomatic. Only serosal lipomas (approximately 10\%) are not seen on endoscopy. Pathology findings 
confirm the presence of mature adipose cells without any sign of malignancy in cyto-nuclear differentiation [9]. Treatment is always surgical as there is no place for pneumatic reduction with fluoroscopic guidance [2] [3]. A more or less extensive resection may sometimes be necessary [2] [3]. Currently, emergency segmental colectomy is deemed the gold standard [1] [2]. Intestinal excision with carcinogenic resection margins may be necessary with the per operative discovery of malignant tumor [3]. Prognosis is directly linked to clinical course of invagination, the extent of lesions and the nature of the obstacle.

\section{Conclusion}

Intestinal intussusception can occur on any segment of the digestive tract. It is rare in adults and is difficult to diagnose. CT remains is the ideal first choiceimaging tool as it allows positive diagnosis of the obstacle. In adults, management is surgical.

\section{References}

[1] Ahn, J.H., Choi, S.C., Lee, K.J. and Jung, Y.S. (2009) A Clinical Overview of a Retrospective Study about Adult Intussusceptions: Focusing on Discrepancies among Previous Studies. Digestive Diseases and Sciences, 54, 2643-2649. https://doi.org/10.1007/s10620-008-0635-x

[2] Lebeau, R., Koffi, E., Diané, B., Amani, A. and Kouassi, J.C. (2066) Acute Intestinal Intussusceptions in Adults: Analysis of 20 Cases. Annals of Surgery, 131, 447-450.

[3] Abou-Nukta, F., Gutweiler, J., Khaw, J. and Yavorek, G. (2007) Giant Lipoma Causing a Colo-Colonic Intussusception. The American Journal of Surgery, 73, 417.

[4] Wulff, C. and Jespersen, N. (1995) Colo-Colonic Intussusception Caused by Lipoma. Acta Radiologica, 36, 478-480.

[5] Zeebregts, C.J.A.M., Geraedts, A.A.M., Blauwgeers, J.L.G. and Hoistsma, H.F.W. (1995) Intussusception of the Sigmoid Colon Because of an Intrarnuscularlipoma Report of a Case. Diseases of the Colon and Rectum, 38, 891-892.

[6] Denie, C., Jacques, P. and Brenard, R. (1995) Spontaneous Exoneration of a Colonic Lipoma. Acta Gastro-Enterologica Belgica, 58, 243-244.

[7] Zamboni, W.A., Fleisher, H., Zander, J.D. and Folse, J.R. (1986) Spontaneous Expulsion of Lipoma per Rectum Occuring with Colonic Intussusception. Surgery, 101, 104-107.

[8] Siddiqui, M.N. and Garnham, J.R. (1993) Submucosal Lipoma of the Colon with Intussusception. Postgraduate Medical Journal, 69, 497-500. https://doi.org/10.1136/pgmj.69.812.497

[9] Hackam, D.J., Saibil, F., Wilson, S. and Litwin, D. (1995) Laparoscopic Management of Intussusception Caused by Colonic Lipomata: A Case Report and Review of the Literature. Surgical Laparoscopy Endoscopy, 6, 155-159.

[10] Nagorney, D.M., Sarr, M.G. and McHrath, D.C. (1981) Surgical Management of Intussusception in the Adult. Annals of Surgery, 193, 230-236.

[11] Weilbaecher, D., Bolin, J.A., Heran, S. and Ogden, W. (1971) Intussusception in Adults. Annals of Surgery, 121, 531-535.

https://doi.org/10.1016/0002-9610(71)90133-4

[12] Kakitsubata, Y., Kakitsubata, S., Nagatomo, H., Mitsuo, H., Yamada, H. and Wata- 
nabe, K. (1993) CT Manifestations of Lipomas of the Small Intestine and Colon. Clinical Imaging , 17, 179-182. https://doi.org/10.1016/0899-7071(93)90105-V

[13] Shoenut, J.P., Semelka, R.C., Silverman, R., Yaffe, C.S. and Micflikier, A.B. (1993) Magnetic Resonance Imaging Evaluation of the Local Extent of Colorectal Mass Lesions. Journal of Clinical Gastroenterology, 17, 248-253.

Submit or recommend next manuscript to SCIRP and we will provide best service for you:

Accepting pre-submission inquiries through Email, Facebook, LinkedIn, Twitter, etc. A wide selection of journals (inclusive of 9 subjects, more than 200 journals)

Providing 24-hour high-quality service

User-friendly online submission system

Fair and swift peer-review system

Efficient typesetting and proofreading procedure

Display of the result of downloads and visits, as well as the number of cited articles Maximum dissemination of your research work

Submit your manuscript at: http://papersubmission.scirp.org/

Or contact ss@scirp.org 